\title{
Signos do vestuário de enfermeira na formatura ${ }^{a}$ \\ Signs of the nurse's clothing at graduation \\ Señales de ropa de enfermería en la formatura
}

Maria Angélica de Almeida Peres ${ }^{1}$ (1) Regina Lucia Muniz de Almeida ${ }^{2}$ (1) Fernanda Batista Oliveira Santos ${ }^{3}$ (D) Gisele Fernandes Tarma Cordeiro ${ }^{1}$ (1)

Tânia Cristina Franco Santos ${ }^{1}$ (1) Angela Aparecida Peters ${ }^{1}$ (D)

1. Universidade Federal do Rio de Janeiro, Escola de Enfermagem Anna Nery. Rio de Janeiro, RJ, Brasil.

2. Faculdade de Ciências Médicas e da Saúde de Juiz de Fora. Juiz de Fora, MG, Brasil.

3. Universidade Federal de Minas Gerais, Escola de Enfermagem. Belo Horizonte, MG, Brasil.
Autor correspondente:

Gisele Fernandes Tarma Cordeiro.

E-mail: gisele_fernandes123@hotmail.com

Recebido em 04/09/2021.

Aprovado em 06/12/2021.

DOI:https://doi.org/10.1590/2177-9465-EAN-2021-0214

\section{Resumo}

Objetivo: Analisar os uniformes usados na cerimônia de formatura de enfermeiras e seus significados para a identidade profissional. Método: Estudou-se uma escola de enfermagem de Minas Gerais, no período de 1947 até 1964 . Pesquisa qualitativa, histórico-social, mediante a qual foram analisados documentos escritos, fotográficos e orais, considerando as bases conceituais de identidade profissional, do sociólogo Claude Dubar, e de vestuário e seus significados simbólicos, de Roland Barthes. Resultados: O uniforme das enfermeiras, usado na formatura, possuía signos de identidade institucional e profissional. Foi constituído pelo clássico vestido branco, com touca e outros acessórios. Conclusões e implicações para a prática: $O$ uniforme de formatura de enfermeiras correspondeu aos avanços da moda e da cientificidade, configurando-se uma marca na construção do papel e consolidação da identidade profissional, contribuindo para a identificação de uma categoria profissional em formação.

Descritores: Enfermeira; Escolas de Enfermagem; História da Enfermagem; Papel Profissional; Vestuário; Identidade Social.

\section{Abstract}

Objective: to analyze the uniforms used in the graduation ceremony of nurses and their meanings for professional identity Method: A nursing school in Minas Gerais was studied from the period of 1947 to 1964. Qualitative, social-historical research, through which written, photographic and oral documents were analyzed, considering the conceptual bases of professional identity, by the sociologist Claude Dubar, and of clothing and its symbolic meanings, by Roland Barthes. Results: The nurses' uniform used at graduation had institutional and professional identity signs. It consisted of the classic white dress, with a cap and other accessories. Conclusions and implications for practice: The nurse's graduation uniform corresponded to the advances in fashion and scientificity, becoming a mark in the construction of the role and a consolidation of professional identity, contributing to the identification of a professional category in training.

Keywords: Nurse; Nursing Schools; History of Nursing; Professional Role; Clothing; Social Identity.

\section{RESUMEN}

Objetivo: Analizar los uniformes utilizados en la ceremonia de graduación de enfermeras y sus significados para la identidad profesional. Método: Se estudió una escuela de enfermería de Minas Gerais, relativo al periodo de 1947 a 1964. Investigación cualitativa, histórico-social, en la que se analizaron documentos escritos, fotográficos y orales, considerando las bases conceptuales de la identidad profesional, del sociólogo Claude Dubar, y de vestuario y sus significados simbólicos, de Roland Barthes. Resultados: El uniforme de las enfermeras, utilizado en la graduación, presentaba señales de identidad institucional y profesional. Consistía en el clásico vestido blanco, con gorra y otros complementos. Conclusiones e implicaciones para la práctica: El uniforme de graduación de enfermeras correspondió a los avances de moda y cientificidad, convirtiéndose en una marca en la construcción y consolidación de la identidad profesional, contribuyendo para la identificación de una categoría profesional en formación.

Palabras clave: Enfermera; Escuelas de Enfermería; Historia de la Enfermería; Rol Profesional; Vestuario; Identidad Social. 


\section{INTRODUÇÃO}

A história da enfermagem mundial reconhece Florence Nightingale como precursora de um movimento de profissionalização da enfermagem considerando que, em 1860, na Inglaterra vitoriana, ela inaugurou a fase da enfermagem moderna. Seu modelo escolarizado visava à aquisição de habilidades e comportamentos, atributos pessoais e profissionais considerados uma forma de melhoria do status social e o reconhecimento pela competência no cuidado aos doentes. Dentre esses atributos de valorização, incluíam-se um vestuário e um comportamento próprio de mulheres moralmente idôneas, que demonstrassem esses valores para a sociedade. ${ }^{1}$

O modelo de escola de enfermagem para mulheres, pensado por Nightingale, alcançou prestígio em várias localidades do mundo, entre elas os Estados Unidos, onde ganhou características próprias relativas à produção e ao cuidado em saúde, delineados pelo capitalismo e taylorismo. ${ }^{2} \mathrm{O}$ modelo anglo-americano foi instituído no Brasil em 1923, com a inauguração da Escola de Enfermeiras do Departamento Nacional de Saúde Pública, trazendo essa concepção de ensino, preocupando-se também com o vestuário acadêmico-profissional. ${ }^{1}$

A enfermagem moderna difundiu-se pelo Brasil, adquirindo força no início da década de 1930, após o Decreto nacional n. 20.109, de 1931, determinar o modelo de ensino da Escola de Enfermeiras Ana Nery (novo nome da escola do DNSP) padrão para as demais escolas de enfermagem do país, que ficou conhecido como "padrão ananéri". A primeira escola a ser criada após tal decreto foi a Escola de Enfermagem Carlos Chagas, em 7 de julho de 1933, pelo Decreto n. ${ }^{-10}$.952, instituição que deu origem à atual Escola de Enfermagem da Universidade Federal de Minas Gerais, na cidade de Belo Horizonte, à época polo do desenvolvimento político e econômico do estado de Minas Gerais. ${ }^{3}$

O contexto político brasileiro em que se instituiu o padrão Ana Néry e criaram-se as escolas de enfermagem nesse formato foi o da chamada Era Vargas (1930-1945), quando houve crescente investimento no desenvolvimento econômico e na indústria de base, com expansão da rede ferroviária, visando à facilitação do transporte de mercadorias para a indústria e comércio ${ }^{4}$. $O$ campo da saúde recebia especial atenção do governo federal, interessado na redução das doenças infectocontagiosas, motivo pelo qual estava investindo, com o auxílio da Fundação Rockefeller, na formação de médicos e enfermeiras. ${ }^{5}$

Após a deposição do Presidente Getúlio Vargas, mediante um golpe ocorrido em 1945, foram convocadas eleições presidenciais, sendo vencedor o General Eurico Gaspar Dutra, cujo governo (1946-1951) aprovou a Constituição de 1946, que congregava princípios liberais e conservadores. Também foi implantado o Plano SALTE, priorizando investimento em saúde, alimentação, transporte e energia, ao tempo que os movimentos trabalhistas eram reprimidos por parte do governo. ${ }^{4}$

Nessa conjuntura, a Escola de Enfermagem Hermantina Beraldo (EEHB) foi criada, em 1946, durante a Reforma do Departamento Estadual de Saúde de Minas Gerais, e inaugurada em 8 de março de 1947, em Juiz de Fora. O nome da escola foi uma homenagem póstuma à esposa de João Beraldo, interventor do estado de Minas Gerais à época da sua criação. Sendo a primeira escola de enfermagem na cidade a diplomar enfermeiras no padrão Ana Nery, sua importância deve-se ao papel que cumpriu na difusão de uma identidade profissional no Brasil - em especial no interior de Minas Gerais -, incorporando emblemas e rituais da escola padrão, também adquiridos pela Escola de Enfermagem Carlos Chagas. ${ }^{3,6}$

Após funcionar por 21 anos sob a administração do Estado de Minas Gerais, passou, em 1968, para a administração da recém-criada Fundação Hermantina Beraldo (FHB), que tinha por objetivo manter o funcionamento da escola, marcado por crises financeiras. O golpe militar de 1964 reconfigurou a sociedade, e as instituições de ensino ficaram sob o alvo do Governo, que aprovou, em 1968, uma reforma universitária, responsável por modificar a estrutura dos cursos de nível superior no Brasil, impactando o ensino de enfermagem, inserido nas universidades em vários estados do país.

Em 1976, ainda no contexto de ditadura militar, a EEHB foi transformada em Faculdade Hermantina Beraldo e mantida fora do cenário universitário, sob a gestão da FHB, que não conseguiu superar as dificuldades financeiras, motivo pelo qual a escola foi extinta em 1978. Tal fato não significou o fim da escola enquanto corpo social, pois aprovou-se um convênio entre o Estado de Minas Gerais, a Universidade Federal de Juiz de Fora (UFJF) e a FHB, criando o Curso de Graduação em Enfermagem da UFJF. Esse convênio é um marco histórico importante para a enfermagem, uma vez que o corpo social da escola foi incorporado e a identidade institucional da EEHB mantida pela UFJF, a qual preservou o uso de uniformes, rituais e cerimônias. ${ }^{6}$

No tocante à formação, as alunas de enfermagem de Juiz de Fora percebiam o uniforme como um símbolo da profissão, um instrumento identificador e diferenciador da enfermeira padrão que, nesse caso, representava uma categoria profissional feminina que galgava espaços rumo à aceitabilidade e reconhecimento da sociedade. Portanto, o uniforme, enquanto símbolo, contribuía na busca de um ideal a ser alcançado, de uma identidade profissional, e o rito da formatura selava os anos de estudos realizados pelas alunas, o trabalho de professores e instituição formadora, como um investimento da sociedade da qual se era parte. ${ }^{6}$

A cerimônia de formatura na EEHB, nos primeiros anos do Curso de Graduação em Enfermagem da UFJF, manteve seus ritos: chamada nominal das formandas, hino nacional, juramento, entre outros. Para a formatura, a aluna vestia o uniforme de enfermeira diplomada, a fim de se apresentar durante a cerimônia com o vestuário próprio da classe profissional a que iria pertencer. Ao considerar a forma de se vestir, na história da humanidade, os uniformes ou fardas tiveram o objetivo de marcar a identidade própria e particular de vários grupos, categorias, tribos, associações, times, classes sociais, alunas de determinada escola, buscando transmitir uma imagem simbólica e uma identidade profissional. ${ }^{7}$

A partir de tais considerações, ressalta-se a importância deste e de outros estudos históricos que desvelem a construção e desenvolvimento de uma categoria profissional, pelas 
oportunidades de reflexão que o passado apresenta para a atualidade e o futuro. Entende-se que essa construção se inicia antes mesmo da formação, tendo em vista as representações sociais já colocadas, e não finaliza com a formatura. Os ritos, símbolos e tradições impulsionam a apropriação das condutas pessoais e de trabalho - que podem ser incorporadas ou refutadas - , influenciando na identidade do profissional.

O objetivo deste artigo é analisar os uniformes usados na cerimônia de formatura de enfermeiras e seus significados para a identidade e papel profissional.

\section{MÉTODO}

O recorte temporal é o período de 1950, ano de formatura da primeira turma da EEHB, até 1964, quando o uso do uniforme nas cerimônias de formatura foi substituído pela beca. Vale realçar que, em 1976, a instituição havia sido renomeada Faculdade Hermantina Beraldo.

Analisaram-se documentos escritos e fotografias de egressas, além de entrevistas produzidas considerando a História Oral Temática com oito ex-alunas que, depois de formadas, trabalharam como professoras da EEHB. Esses registros, elaborados na dissertação de mestrado intitulada "Formação de Enfermeiras na Cidade de Juiz de Fora: uniforme e identidade na Escola de Enfermagem Hermantina Beraldo (1947-1978)", 8 foram incorporados ao acervo oral do Centro de Documentação da Escola de Enfermagem Anna Nery, da Universidade Federal do Rio de Janeiro.

Os documentos consultados para a presente análise foram: livros de registros e ata de formatura da primeira turma da EEHB, pertencentes a UFJF; documentos sobre EEHB localizados no Departamento de Pessoal da Gerência Regional de Juiz de Fora; legislações e reportagens jornalísticas referentes à EEHB, publicadas em Juiz de Fora, no Jornal Diário Mercantil; e relatórios da Santa Casa de Misericórdia de Juiz de Fora. O registro fotográfico dos uniformes usados na formatura da EEHB foi encontrado nos jornais da época ou cedidos pelas ex-alunas, colaboradoras deste estudo. $^{9}$

A opção em complementar os dados escritos com dados orais ocorreu por considerar que o vestuário possui diferentes linguagens, e uma delas corresponde ao vestuário real - aquele que somente quem viu, pegou, usou a roupa, conhece. A história oral permite trabalhar a memória como fonte histórica, acrescentando dados aos demais documentos, pois, ao ampliar a possibilidade de pesquisa, viabiliza conhecer detalhes vividos pelas pessoas em determinada época. ${ }^{9-10}$. Foram incluídas como colaboradoras oito ex-alunas da EEHB, entrevistadas pela técnica da História Oral Temática, as quais gravaram, transcreveram e validaram as próprias falas.

Os dados passaram por triangulação e categorização temática guiada pelo objetivo do estudo. O referencial analítico adotado baseou-se no conceito de identidade do sociólogo Claude Dubar, ${ }^{11}$ e de vestuário e seus significados simbólicos, de Roland Barthes ${ }^{12}$, que permitiram uma discussão reflexiva e crítica acerca do significado social atribuído ao uniforme de formatura, um dos elementos contribuintes para a construção da identidade dos grupos profissionais - nesse caso, das enfermeiras

As questões éticas foram respeitadas e o projeto aprovado por Comitê de Ética em Pesquisa pelo Parecer $n . \stackrel{0}{168.815}$, de 2012. As colaboradoras foram identificadas no texto pela letra $C$ seguida do número correspondente à ordem de realização da entrevista.

\section{RESULTADOS}

As escolas de enfermagem criadas no padrão Ana Nery seguiram as normas ritualísticas principais da escola de referência, que incluíam, além do vestuário de gala, o juramento, o hino nacional e a recepção de diploma, elementos que integravam o ritual de passagem da vida de estudante para a vida profissional.

Na cerimônia de formatura da primeira turma, a EEHB instituiu como uniforme de gala (Figura 1) um vestido de linho branco, de mangas compridas, sem punhos. O modelo da saia do vestido era evasê, de cintura bem marcada, com um cinto feito do mesmo tecido. O comprimento deveria ser abaixo do joelho, e a blusa (parte superior do vestido) era abotoada lateralmente por quatro botões brancos. Complementavam o uniforme de gala uma touca branca de organdi engomada, uma capa de pelerine ou lã fina branca, de comprimento abaixo dos joelhos, cobrindo todo o vestido e presa no pescoço por uma gola com um botão, coberto pelo broche contendo a insígnia da escola Os sapatos eram fechados, na cor branca, e as meias eram cor da pele, como descrito pelas ex-alunas:

O uniforme de gala era um uniforme de linho branco, abotoado do lado. A capa era de lã, uma lã mais fininha. A touca era de organdi, era bem bonita. Ficava engomada (C1).

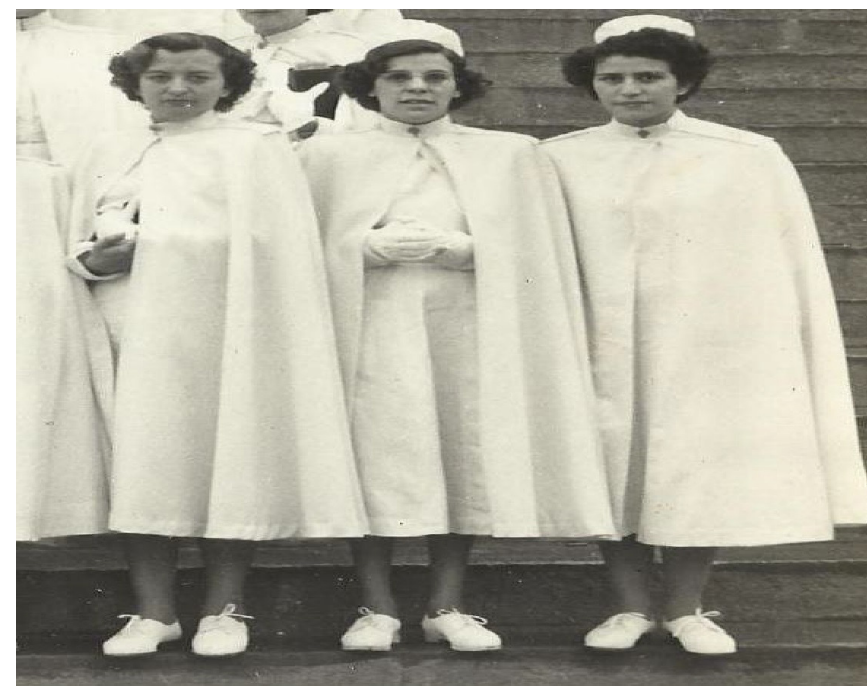

Figura 1. Fotografia de alunas no dia da formatura na EEHB - Ano de 1963.

Fonte: Família da Enfermeira Conceição Lessa 
Era um vestido. Parecia mais uma roupa japonesa. Abotoada de lado, até no ombro, e tinha uma capa que a gente chamava de pelerine, cobria até o joelho (C3).

Tinha uma capa. Ela era tipo gola de padre e o resto era godê, de lã. Esta capa a gente usava em festividades (C4).

A capa (Figura 1), conforme descrita pelas ex-alunas, era confeccionada de um tecido mais pesado e encorpado do que o vestido. Para prender a capa, usava-se um broche contendo a insígnia da EEHB:

O acessório que tinha era um distintivo com um triângulo escrito: arte, ciência e ideal (C6).

A gente tinha que comprar um broche escrito Escola de Enfermagem de Juiz de Fora (C5).

Esse foi o uniforme usado nas formaturas até 1964, quando a beca foi estabelecida na instituição.

O broche (Figura 2) era constituído de vários elementos simbólicos. Externamente, possuía um círculo de folhas douradas que, segundo as colaboradoras, era folheado a ouro; sobre o círculo de folhas, trazia uma cruz amarela, com bordas brancas; sobre a cruz - que tinha a forma da Cruz de Malta -, dois círculos se justapunham: um branco, gravado com o nome "Escola de Enfermagem Juiz de Fora", e o outro, central, de cor azul-marinho, mostrando um triângulo, sendo que cada lado exibia uma das palavras do lema "Arte, Ciência, Ideal" (palavras de Florence Nightingale sobre a profissão de enfermeira), bem como a data de criação da escola, 1947; o centro do triângulo ostentava a lâmpada grega, símbolo da Enfermagem Moderna, desenhada em dourado.

A Figura 3 registra as diplomadas da primeira e da segunda turma da EEHB, no dia da formatura, com algumas professoras, dentre elas a diretora da escola. Observam-se as alunas e as professoras com o uniforme de gala. $O$ que se nota de diferente é o modelo de algumas toucas de professoras, que usam a de

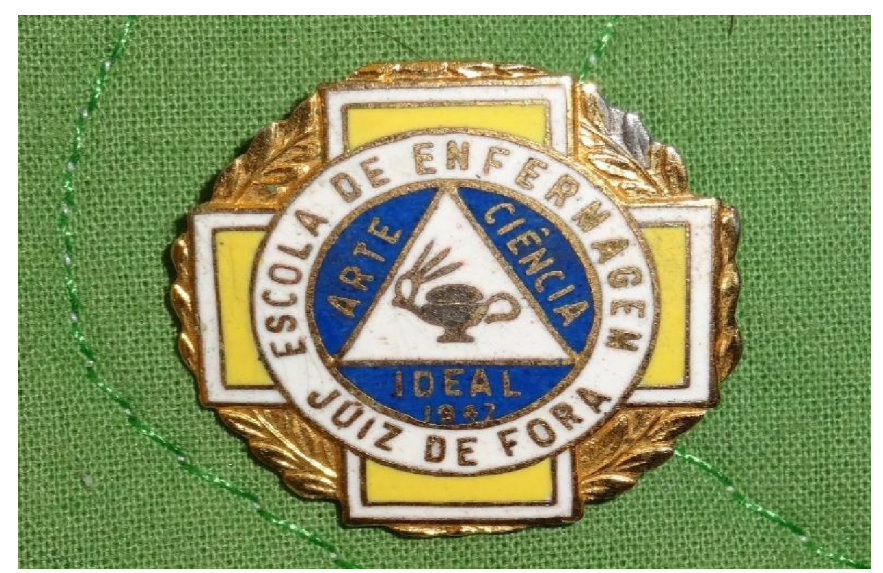

Figura 2. Fotografia do broche utilizado na gola da capa. Fonte: Acervo pessoal de Ana Margareth Aarestrup Arbex sua escola de formação (peça semelhante ao véu), diferente da touca das diplomadas pela EEHB. As duas turmas se formaram no mesmo dia, embora tenham iniciado o curso em momentos diferentes (a primeira em março e a segunda em junho). $\mathrm{Na}$ ilustração, também se observa a postura corporal das alunas, indicativa do momento solene do qual estavam fazendo parte.

A Figura 4 registra, em maiores detalhes, o uniforme de gala usado na formatura das alunas do ano de 1959, na qual se visualiza o uso de luvas e o broche que prendia a capa. A utilização de vestuário (uniforme de gala) na cerimônia de formatura pode ser entendida como signo importante na consolidação da identidade da enfermeira formada pela EEHB, e tornou-se padrão para todas as formaturas subsequentes, sem alterações até o ano de 1964, último antes da adoção da beca. Destacam-se a capa, sobrepondo-se ao vestido, os sapatos brancos e a touca no alto da cabeça.

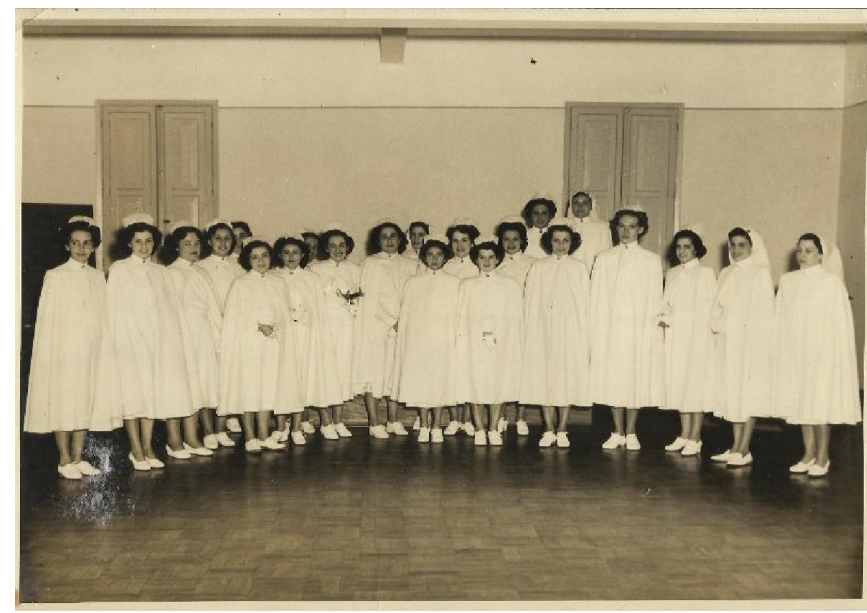

Figura 3. Fotografia da primeira e segunda turmas da EEHB - Cerimônia de Formatura das Pioneiras, ocorrida em 1950. Fonte: Acervo pessoal de Maria José Otoni

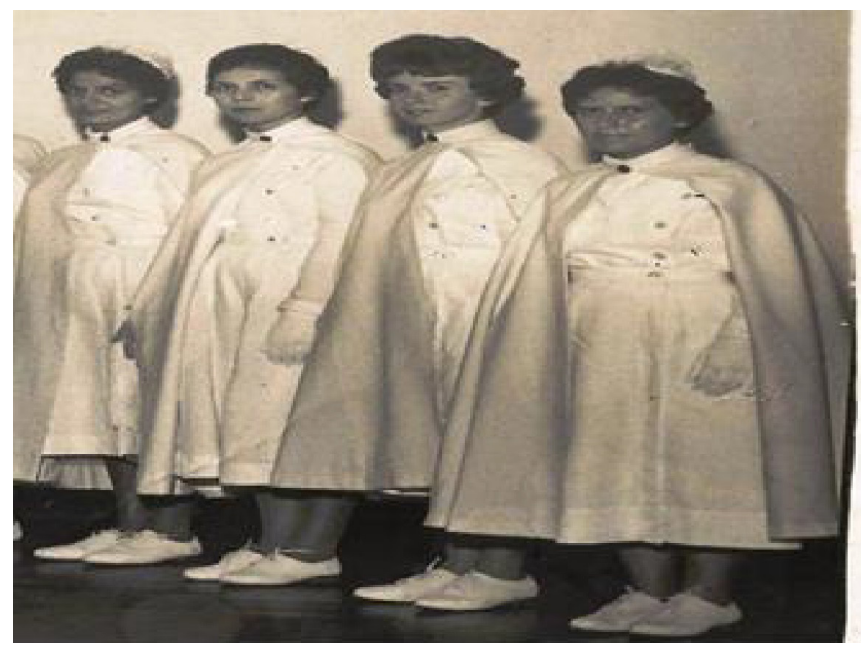

Figura 4. Formandas da EEHB, turma de 1959. Fonte: Acervo pessoal de Raquel Aldbert Delage 


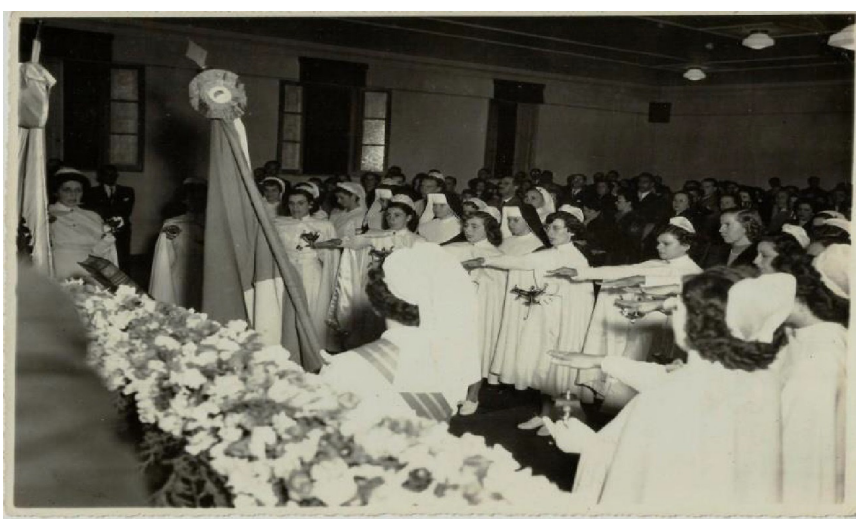

Figura 5. Fotografia do Juramento em Cerimônia de Formatura da EEHB - Ano de 1950.

Fonte: Acervo Pessoal de Rachel Audebert Delage

Na primeira formatura da EEHB, em 1950, os símbolos entre os quais podem ser destacados a lâmpada, o broche e 0 uniforme - já faziam parte desta cerimônia e contribuíam para a construção da identidade da enfermeira. Outros elementos importantes também compunham a solenidade, como os discursos e juramentos.

$\mathrm{Na}$ Figura 5, registra-se o momento do juramento das alunas da EEHB, em que se destaca a postura solene, com o braço direito estendido na direção das bandeiras e a lâmpada na mão esquerda. É possível identificar somente a bandeira do Brasil; a segunda bandeira, de acordo com os rituais de outras escolas, provavelmente é a do município de Juiz de Fora ou da escola.

A cerimônia de formatura da turma pioneira da EEHB - constituída pelas duas turmas ingressantes em 1947 - foi prestigiada por figuras importantes, civis e militares. $\mathrm{O}$ evento ganhou destaque na imprensa da cidade de Juiz de Fora, significando o reconhecimento da enfermeira profissional naquele momento em que a saúde se destacava nos projetos de desenvolvimento na região de Minas Gerais.

A notícia do jornal "O Diário Mercantil" refletiu a notoriedade desse evento de formatura. Tratando-se de veículo de comunicação de prestígio em Juiz de Fora, ele divulgou, no dia 15 de agosto de 1950: "As Primeiras Diplomadas de Juiz de Fora".

A cobertura pela mídia jornalística, da formatura das enfermeiras, agregou valor ao ato solene e divulgou a imagem da profissional, que a partir daquele momento seria inserida nos serviços de saúde de Juiz de Fora, levando até a comunidade a qualificação profissional, e estimulando outras mulheres a escolherem a profissão de enfermeira, matriculando-se na escola existente em sua cidade.

\section{DISCUSSÃo}

A semelhança com o uniforme das professoras tem valor emblemático e fundamental, uma vez que deveria simbolizar o arquétipo da enfermeira padrão a ser reproduzido e incorporado na sociedade, na expectativa de aceitabilidade, identificação e legitimidade da profissão. ${ }^{13,14} \mathrm{O}$ uniforme usado na formatura era o de enfermeira diplomada na sua versão de gala (uniforme de gala).

O uniforme na enfermagem foi essencial para aproximar, pela imagem, mulheres de diferentes classes sociais, que se formavam enfermeiras em cursos de nível superior, possibilitando a reconfiguração da profissão na sociedade. A conquista da mulher por novos espaços tem relação direta com o trabalho $e$ independência financeira, o que a formação em enfermagem, no século XX, ajudou a adquirir. Assim, a cerimônia de formatura de enfermeiras, por se tratar de uma escola somente para mulheres, no período, constituía-se em uma resposta à sociedade sobre a importância do trabalho e do preparo profissional feminino.

A formatura - ou conclusão das etapas regulares exigidas no processo de formação escolar e profissional - sela os anos de estudos, delimitando a aquisição de conhecimento específico que profissionaliza uma pessoa com a qualificação necessária para o trabalho. ${ }^{13}$

Existem inúmeros significados contidos no ato de se vestir para receber um diploma. Formar-se como um profissional compreende mais do que ser diplomado: envolve a importância conferida ao rito da formatura, às vestimentas especiais, ao simbolismo da cerimônia em si, tanto para os formandos quanto para os pais que acompanharam a trajetória dos filhos, bem assim o cumprimento do papel da escola como educadora e formadora de profissionais para a sociedade na qual está inserida. ${ }^{11}$

Ao analisar a forma que as profissões se consolidam no interior da sociedade, Dubar ${ }^{11}$ buscou compreender essa dinâmica por meio do termo burocratização das carreiras, pelo fato de o diploma ser visto como concretização de determinada profissão pelo diplomando, que precisou vencer várias etapas e cumprir determinadas exigências do curso, profissão da qual o grupo diplomado passa a fazer parte.

O diploma, integrando esse momento solene da formatura, na consolidação das profissões no âmbito da sociedade, é considerado uma normatização das carreiras, a legitimação da formação, na qual o aluno ingressou pela via universitária ou profissional. Assim, o grupo profissional, a partir da formatura, passa a ser incluído em uma organização fechada, preocupada com seu desenvolvimento, seu funcionamento interno e o respeito a seus códigos profissionais e éticos. ${ }^{11}$

Nesse sentido, a enfermagem, tendo em vista a inclinação natural ou a vocação do seu corpo de trabalhadores, incorpora um conjunto de normas, de regras, de conhecimentos científicos que contribuem para o processo de afirmação da profissão na esfera social. A enfermagem moderna, ao ser implantada no Brasil na década de 1920, manteve a cerimônia de formatura como um momento de dar visibilidade social ao grupo de mulheres que se dedicaram aos estudos para o bem do próximo, em um ato de contribuir no desenvolvimento da nação, ${ }^{14} \mathrm{e}$ destacou o uniforme branco da enfermeira com a touca como o símbolo mais importante da diplomada, atribuindo mais valor a ele do que ao "canudo" em si, pois o vestuário era visível e a acompanharia aonde fosse. 
A formatura configura-se um signo associado a uma memória afetiva para aqueles que vivenciaram o processo de construção do saber, na busca de profissionalização. Esta é relembrada como marco da trajetória do ser humano e de seus pares e familiares, permitindo revisitar aquele momento. É nesse sentido que os atores do processo guardam objetos físicos - fotos e roupas -, eternizando aquilo que é significativo. ${ }^{15}$

Assim, a formatura significa, para os alunos que se apropriam de seus diplomas -e os que se encontram no processo de formação -, o objetivo de se tornarem profissionais com todos os direitos que a profissão escolhida adquiriu na sociedade. O rito tradicional da "Passagem da Lâmpada", instituído pela Escola de Enfermagem do Departamento Nacional de Saúde Pública, também estava presente nas cerimônias da EEHB. A alusão à lâmpada é para relembrar Florence Nightingale, que ficou mundialmente conhecida como a "Dama da Lâmpada" ao cuidar dos feridos na Guerra da Crimeia. ${ }^{14}$

Ser eleita a Dama da Lâmpada era reforçar o modelo de enfermeira diplomada com os atributos desejáveis a cada época, a partir de uma aluna exemplar em conduta e em conhecimento, atestados ao longo do curso pelos graus alcançados. Essa aluna formanda deveria influenciar o seu grupo na construção da identidade profissional, com o perfil desejado pela escola.

O juramento na solenidade de formatura, segurando na mão esquerda a lâmpada da enfermagem, apontava a introjeção dos ideais do exercício da profissão a serem reforçados nos locais onde a enfermeira estivesse presente. $O$ ato de jurar significava entrar em uma comunidade moral, para a qual era necessário prestar compromisso por pertencer a determinada corporação, detentora de direitos e deveres regulamentados numa perspectiva ético-legal, conhecimento e técnicas de enfermagem a serem assimiladas durante o percurso formativo para o fortalecimento da categoria profissional. ${ }^{11,16}$

O vestido branco de linho, destacado pelas alunas colaboradoras desta pesquisa, marcava também o momento solene, majestoso, o auge que estavam vivenciando, mostrando a posição de profissional que assumiriam logo após a formatura. Nesse sentido, o tecido de linho - utilizado desde a antiguidade greco-romana, para as vestes dos monges e sacerdotes, ${ }^{16}$ bem como para confecção de roupas mais finas - passa a ter valor simbólico, representando o ato de festejar uma conquista importante na vida das alunas, ou seja, a formatura. ${ }^{17,18}$

Ao destacarem o uso da capa na solenidade da formatura, percebe-se o grau de importância conferido à peça pelas colaboradoras, e o valor simbólico que esse traje conferiu às enfermeiras no ato da diplomação, quando começaram a fazer jus da autoridade de profissionais. A capa, como componente da vestimenta de formatura, impressionava inclusive os funcionários da escola pela imponência que a vestimenta refletia.

Assim, imagem e identidade profissional eram trabalhadas na formação de enfermeiras na EEHB, com vistas a despertar, na sociedade, respeito, admiração e confiança nessas profissionais que prestariam cuidados em saúde à população juiz-forana.
A construção da identidade também se faz a partir de situações que marcam a vida do ser humano, ideologias e comportamentos observados e compartilhados no âmbito das relações desenvolvidas na sociedade. Ela pode ocorrer no seio da família, nos núcleos religiosos, nas escolas, mas também nos momentos considerados de adversidade, como, no caso particular, da instituição de saúde. Encontros e situações se transformam em divisores, marcos que mobilizam as pessoas a buscarem novas perspectivas de enfrentamento. Tais situações acabam se tornando grandes motivadoras ao exercício de alguns ofícios, atividades ou profissões. ${ }^{11,19}$

A construção da identidade se faz diante da diferença, ou seja, em contraponto com outras identidades existentes. Para que uma identidade se sobressaia, ela precisa ser comparada a outra, diferente ao que está posto. Nesse sentido, a marcação das diferenças, presente na linguagem dos uniformes da enfermeira, por meio de símbolos como a touca, o broche, entre outros, contribui para a identidade profissional. Qualquer identidade depende da diferença. ${ }^{11,19}$

Desse modo, os uniformes refletem a cultura, sendo indissociável da moda que se adapta aos costumes regionais e temporais. O uniforme das enfermeiras em Juiz de Fora, o mesmo usado no dia da formatura, cumpria o seu papel de acentuar a divisão de classe na enfermagem juiz-forana, fortalecendo o impulso de cada um de nós (necessidade de afirmação como pessoa) e o socializador (necessidade de afirmação como membro do grupo). ${ }^{11}$

Refletir sobre a formação da identidade dos profissionais inclui a questão do uso dos uniformes, quando se considera a roupa como componente importante de demonstração e afirmação da individualidade. Escolher o que vestir, incluindo-se o modelo, a cor e os acessórios, reflete todo um estilo e uma maneira peculiar de pensar sobre si e o mundo em que se vive. ${ }^{20,21}$

Dessa forma, o vestido de linho e a touca branca eram peças evidenciadas num vestuário que dignificava a enfermeira que o usava. A imagem construída - especialmente por essas peças, e pela postura dessas profissionais -colocava-as no seleto grupo de enfermeiras, que na capital da república, anos antes, na década de 1920, fora apresentado à sociedade brasileira como modelo e exemplo de profissional idônea e qualificada. ${ }^{22}$

Outros estudos destacaram a importância do uniforme usado nas escolas de enfermagem na primeira metade do século XX, no Brasil, visando a construção de uma identidade profissional contemporânea para mulheres que estudavam em escolas que seguiram o modelo padrão, levando a alterações nos modelos, comprimento e outros detalhes do uniforme, a fim de acompanhar o desenvolvimento profissional e científico da profissão. Frases como "estar na moda" ou "fora de moda" acompanham o cotidiano das pessoas, não só em relação à vestimenta, mas também aos comportamentos. 3,7,14,22-23

Os resultados deste estudo corroboram os resultados trazidos por autores que tratam do tema uniformes. Há uma forte necessidade social de identificar os grupos profissionais e, na área da saúde, fato construído em todos os países 
conforme a enfermagem foi se profissionalizando. O uniforme não é uma peculiaridade da enfermagem e sim dos grupos profissionais, traduzindo a respectiva identidade coletiva pela qual se estabelecem hierarquias, atribuições, competências, entre outras características profissionais. ${ }^{6-7,20-21,24}$

A moda carrega consigo uma maneira particular de intensificar detalhes das vestimentas, demarcando aspectos que incorporam determinados conceitos, em um certo tempo e espaço, às vezes curto, mas intensamente vividos. Assim, a moda se apresentava nos uniformes como uma linguagem que expressava o desenvolvimento da profissão de enfermeiras na sociedade, ao tempo que revestia as formandas de orgulho e expectativa para iniciar o exercício profissional e se exibir, usando aquele elemento de identificação. ${ }^{12}$

Como substituto do corpo o vestuário, com seu peso, participa dos sonhos fundamentais do homem, do céu e da caverna; da vida sublime e do enterramento; do voo e do sono: é com seu peso que o vestuário se torna asa ou mortalha, sedução ou autoridade. Os trajes cerimoniais são pesados: a autoridade é um tema de imobilidade, de morte. Os trajes que festejam as bodas, o nascimento, a vida, são vaporosos e leves; o peso do tecido da roupa confere uma demarcação à matéria, associada à força e autoridade que melhor define um tecido do qual o vestuário é composto. ${ }^{12}$

O uniforme de enfermeira usado na formatura seria também incorporado ao seu exercício, tornando-se elemento de identificação daquele grupo formado na EEHB, diferenciando as profissionais das demais categorias de enfermagem. A qualificação profissional e a superioridade hierárquica dentro da equipe de enfermagem foram ditadas nos anos estudados pelo uniforme de enfermeira, funcionando assim como elemento simbólico da profissão, destacando-se dentro da equipe de enfermagem o uso da touca de enfermeira e o vestido branco.

\section{CONCLUSÕES E IMPLICAÇÕES PARA A PRÁTICA}

O estudo fez sobressair mais do que o uso do uniforme de formatura e suas características, registrando parte do cotidiano das alunas durante a sua formação profissional e estratégias institucionais para que construísse uma identidade profissional e institucional.

Os uniformes das alunas da EEHB, como fragmento de um universo chamado "vestuário", contribuíram para a identificação de uma categoria profissional em formação. Ademais, transmitiram tanto uma imagem quanto uma linguagem emblemática para alunos, professores e demais profissionais da classe, que compartilharam do mesmo momento histórico e social em que a escola se manteve em funcionamento, transmitindo novos conceitos da ciência, da técnica e um ideal de assistência à saúde a ser prestado à população.

Estudos de história da enfermagem sobre uniformes vêm contribuindo para a compreensão do papel simbólico e da linguagem não verbal, atribuídos ao vestuário da enfermagem. Usados até hoje, no século XXI, adaptados às circunstâncias assistenciais e às influências da moda, conforme o contexto histórico vivido, são motivos de reflexão por parte de estudantes e professores. Eles discutem qual seria a sua melhor apresentação (modelo, cor, acessórios), bem como seu uso, apesar de existirem normas regulamentadoras do vestuário de profissionais de saúde, tanto nos serviços quanto nas instituições de ensino.

Afirma-se que o uniforme usado na formatura pelas alunas de enfermagem da EEHB se configurou uma marca, um signo essencial no movimento de construção e consolidação da identidade da enfermeira na cidade de Juiz de Fora, uma vez que foi reconhecido como um objeto de identificação das enfermeiras diplomadas na cidade, sendo utilizado por 31 anos.

Este estudo cria a possibilidade, tanto para a geração presente quanto para aquelas vindouras, de acesso ao conhecimento à compreensão e interpretação da história - no caso específico, da EEHB -, e da importância dos uniformes na contribuição da formação profissional, a qual se manifesta sempre em movimento contínuo e inexorável de mudanças, em que cada ser humano é um protagonista de seu próprio tempo e espaço.

A limitação caracterizou-se pela escassez de documentos escritos relacionados à EEHB, que foram arquivados na antiga Sede da Escola (atual Gerência Regional de Saúde de Juiz de Fora) e, posteriormente, transferidos para outros acervos devido à necessidade de reforma do prédio. Nesse trajeto, a maioria dos documentos extraviou, limitando o levantamento de informações. Cabe ressaltar que a limitação citada não fragilizou os resultados da pesquisa, todavia evidencia uma lacuna que ainda deve ser trabalhada por outras pesquisas.

\section{CONTRIBUIÇÕES DOS AUTORES}

Desenho do estudo. Maria Angélica de Almeida Peres. Regina Lucia Muniz de Almeida.

Coleta ou produção dos dados. Maria Angélica de Almeida Peres. Regina Lucia Muniz de Almeida. Fernanda Batista Oliveira Santos. Gisele Fernandes Tarma Cordeiro. Tânia Cristina Franco Santos. Angela Aparecida Peters.

Análise de dados. Maria Angélica de Almeida Peres. Regina Lucia Muniz de Almeida. Fernanda Batista Oliveira Santos. Gisele Fernandes Tarma Cordeiro. Tânia Cristina Franco Santos. Angela Aparecida Peters.

Interpretação dos resultados. Maria Angélica de Almeida Peres, Regina Lucia Muniz de Almeida. Fernanda Batista Oliveira Santos, Gisele Fernandes Tarma Cordeiro. Tânia Cristina Franco Santos. Angela Aparecida Peters.

Redação e revisão crítica do manuscrito, Maria Angélica de Almeida Peres. Regina Lucia Muniz de Almeida. Fernanda Batista Oliveira Santos. Gisele Fernandes Tarma Cordeiro. Tânia Cristina Franco Santos. Angela Aparecida Peters.

Aprovação da versão final do artigo. Maria Angélica de Almeida Peres. Regina Lucia Muniz de Almeida. Fernanda Batista Oliveira Santos. Gisele Fernandes Tarma Cordeiro. Tânia Cristina Franco Santos. Angela Aparecida Peters 
Responsabilidade por todos os aspectos do conteúdo e a integridade do artigo publicado. Maria Angélica de Almeida Peres, Regina Lucia Muniz de Almeida, Fernanda Batista Oliveira Santos, Gisele Fernandes Tarma Cordeiro. Tânia Cristina Franco Santos. Angela Aparecida Peters.

\section{EDITOR ASSOCIADO}

Antonio José de Almeida Filho (1)

\section{EDITOR CIENTÍFICO}

Ivone Evangelista Cabral (D)

\section{REFERÊNCIAS}

1. Figueiredo $M$, Peres $M$. The identity of the female nurse: a reflection from the perspective of Dubar. Referência. 2019 out;4(20):149-54. http://dx.doi.org/10.12707/RIV18079.

2. Silva TWME, Velloso ISC, Araújo MT, Galdino CS, Pires Jr JF, Nobre T. Circulação do poder-saber na constituição das práticas profissionais de médicos e enfermeiros. Rev Baiana Enferm. 2018;32:e28234. http:// dx.doi.org/10.18471/rbe.v32.28234.

3. Santos FBO, Carregal FAS, Rodrigues RD, Marques RC. Brazilian nursing history (1950-2004): what has been discussed in the literature? Rev Enferm Cent-oeste Min. 2018;8:e1876.

4. Fausto B. História concisa do Brasil. São Paulo: Edusp; 2015.

5. Campos PFS, Carrijo AR. llustre inominada: Lydia das Dôres Matta e enfermagem brasileira pós-1930. Hist Cienc Saude. 2019 jan/ mar;26(1):165-85.

6. Almeida RLMD, Rodrigues AAP, Tarma GF, Figueiredo MAGD, Almeida Fo AJ, Santos TCF et al. Clothing and professional identity in the training of nurses in the city of Juiz de Fora. Rev Bras Enferm. 2018;71(suppl 4):1548-55. http://dx.doi.org/10.1590/0034-7167-20170522. PMid:30088623.

7. Lurie A. A linguagem das roupas. Rio de Janeiro: Rocco; 1997.

8. Almeida RLMD. Formação de Enfermeiras na Cidade de Juiz de Fora uniforme e identidade na Escola de Enfermagem Hermantina Beraldo (1947-1978).[dissertação]. Rio de Janeiro: Escola de Enfermagem Anna Nery/Universidade Federal do Rio de Janeiro; 2014.
9. Meihy JCSB, Holanda F. História oral: como fazer como pensar. 4th ed. São Paulo: Contexto; 2010.

10. Araújo FE. Casas de farinha e farinhadas: cultura material, história oral e memória. Cadernos CEOM. 2015 jun;28(42):45-52.

11. Portelli A. Un travail de relation: quelques observations sul histoire orale. Clio Revue domande et tessinoise sur les didactiques de histore. Trilhas da História [Internet]. 2017 [citado 2020 mar 28];7(13):182-95 Disponível em: https://periodicos.ufms.br/index.php/RevTH/article/ view/5306/4019

12. Dubar CA. Socialização: construção das identidades sociais e profissionais. São Paulo: Martins Fontes; 2005.

13. Barthes R. Sistema de moda. São Paulo: Martins Fontes; 2009.

14. Silva GTR, Almeida DB, Oliveira NL, Laitano ADC, Santos VPFA, Queirós PJP. Estudos sobre a imagem das enfermeiras: cinco décadas entre a imagética e suas repercussões. Esc Anna Nery. 2020;24(4):e20200063. http://dx.doi.org/10.1590/2177-9465-ean-2020-0063.

15. Coelho Jr NM, Cunha MYS. Os quadros de formatura do Colégio Coração de Jesus (1922-1929): contribuições para o estudo da História da Educação em Santa Catarina. Cadernos CEOM. 2016;29(44):71-8.

16. Aperibense PGGS, Silva CG, Santos TCF, Almeida Fo AJ, Nelson $S$, Peres MAA. The uniform of nursing students: a strategy for the construction of professional identity (1950-1960). Texto Contexto Enferm. 2019;28:e20170593. http://dx.doi.org/10.1590/1980-265xtce-2017-0593.

17. Coelho Jr NM. Laços e enlaces: sociabilidades, personagens e distinções nos quadros de formatura. Anais do II Seminário Internacional História do Tempo Presente; 2014 out. 13-15; Florianópolis. Florianópolis: Programa de Pós-Graduação em História da Universidade do Estado de Santa Catarina (UDESC); 2014.

18. Dubar C. A crise das identidades: a interpretação de uma mutação. São Paulo: Edusp; 2009.

19. Laver J. A roupa e a moda: uma história concisa. São Paulo: Cia das Letras; 1990.

20. Avelar E. O imaginário da formatura: as raízes da cultura bacharelesca e a construção do imaginário da formatura. São Paulo: Iventura; 2012.

21. Andrade C. A construção da identidade, autoconceito e autonomia em adultos emergentes. 2016; Psic Esc Educ. 20(1):137-46.

22. Santos C. Clothing as symbolic capital: youth identitary process. 2017;(1):5-96. http://dx.doi.org/10.20287/eikon-n01-a07.

23. Rajani DTR, Neenu R. Study on preference for clothing among nursing mothers. Int J Home Sci. 2016;2(3):329-31.

24. Peres MAA, Padilha MICS. Uniform as a sign of a new nursing identity in Brazil (1923-1931). Esc Anna Nery. 2014;18(1):112-21. http://dx.doi. org/10.5935/1414-8145.20140017.

\footnotetext{
${ }^{a}$ Artigo extraído da Dissertação de Mestrado em enfermagem intitulada: Formação de Enfermeiras na Cidade de Juiz de Fora: uniforme e identidade na Escola de Enfermagem Hermantina Beraldo (1947-1978). Autora: Regina Lucia Muniz de Almeida. Orientadora: Dr. ${ }^{\text {a }}$ Maria Angélica de Almeida Peres. Programa de Pós-graduação Stricto Sensu da Escola de Enfermagem Anna Nery. Universidade Federal do Rio de Janeiro, Rio de Janeiro. 2014.
} 